\title{
PROBABILISTIC ASSESSMENT OF SEISMIC DRIFT DEMANDS FOR FRAME STRUCTURES IN NEAR-FAULT REGIONS
}

\author{
Jan Tysh-Shang \\ Department of Civil Engineering, Feng Chia University, Taichung, Taiwan, R.O.C \\ Lin Chiung-Yueh \\ Department of Civil Engineering, Feng Chia University, Taichung, Taiwan, R.O.C, yl770@ylvs.chc.edu.tw \\ Wu Chun-Wei \\ Department of Civil Engineering, Feng Chia University, Taichung, Taiwan, R.O.C
}

Follow this and additional works at: https://jmstt.ntou.edu.tw/journal

Part of the Civil and Environmental Engineering Commons

\section{Recommended Citation}

Tysh-Shang, Jan; Chiung-Yueh, Lin; and Chun-Wei, Wu (2010) "PROBABILISTIC ASSESSMENT OF SEISMIC DRIFT DEMANDS FOR FRAME STRUCTURES IN NEAR-FAULT REGIONS," Journal of Marine Science and Technology. Vol. 18: Iss. 3 , Article 4.

DOI: $10.51400 / 2709-6998.1880$

Available at: https://jmstt.ntou.edu.tw/journal/vol18/iss3/4

This Research Article is brought to you for free and open access by Journal of Marine Science and Technology. It has been accepted for inclusion in Journal of Marine Science and Technology by an authorized editor of Journal of Marine Science and Technology. 


\section{PROBABILISTIC ASSESSMENT OF SEISMIC DRIFT DEMANDS FOR FRAME STRUCTURES IN NEAR-FAULT REGIONS}

\section{Acknowledgements}

This research investigation is funded by the National Science Council of Taiwan, R.O.C., under grant number NSC93-2211-E-035-015. This financial support is gratefully acknowledged. The reviewers' opinions and suggestions are also appreciated. 


\title{
PROBABILISTIC ASSESSMENT OF SEISMIC DRIFT DEMANDS FOR FRAME STRUCTURES IN NEAR-FAULT REGIONS
}

\author{
Tysh-Shang Jan*, Chiung-Yueh Lin*, and Chun-Wei Wu*
}

Key words: probabilistic estimation, inter-story drift ratio, near-fault earthquake, spectral displacement, modification factors.

\begin{abstract}
The purpose of this paper is to provide engineers with a rapid procedure to assess the maximum inter-story drift for generic moment-resisting frame (GMRF) structures in nearfault regions. In this procedure, the maximum inter-story drift demand of a structure can be evaluated by starting from the median value of elastic spectral displacement at the first period of the structure, and then amplifying it with some modification factors. Statistical parameters (medians and dispersions) of the distributions of these factors are obtained by performing linear, and nonlinear, dynamic simulations on codecompliant steel GMRF structures, to near-fault ground motions during Taiwan's Chi-Chi earthquake in 1999. Statistical equations that use the obtained medians and dispersions are provided for engineers to evaluate the maximum inter-story drift.

Through the study on the simulation data of medians and dispersions of these factors, it is found that the dispersion of $\alpha_{u}$ - which has been neglected in the previous study by Gupta and Krawinkler - has a great effect on determining the maximum inter-story drift demand of structures. In addition, care must be taken when buildings being designed are less than $2 \mathrm{~km}$ from the fault, since the medians $\hat{\alpha}_{\theta}$ of structures in this region are relatively larger than those of the other regions $(2 \mathrm{~km}<r<12 \mathrm{~km})$. All statistics obtained in this study are steady and reliable, regardless of the number of stories. Therefore, this rapid method for evaluating seismic demands should be valuable and helpful for engineers in doing the preliminary design.
\end{abstract}

Paper submitted 12/19/08; revised 05/01/09; accepted 06/11/09. Author for correspondence: Chiung Yueh Lin (e-mail: yl770@ylvs.chc.edu.tw).

*Department of Civil Engineering, Feng Chia University, Taichung, Taiwan, R.O.C.

\section{INTRODUCTION}

Ground motion records from recent earthquakes show that, near-fault ground motions are different from far-field ground motions, in that they often contain strong coherent dynamic long-period pulses and permanent ground displacements $[5,6$, 13, 20, 21]. Characteristics of near-fault ground motions warrant special consideration due to their severe and impulsive effects on structures. These characteristics are unique compared to far-field ground motions, upon which nearly all seismic design criteria are based.

In recent years, many researchers have focused their research on performance evaluation methods $[1,2,4,7,10]$. The advantage of these methods is that the seismic demands roof displacements, story drift ratios, and element ductility ratios - can be estimated, and thus controlled within the structural limits for different intensity levels of earthquakes. In these performance-based design methods, seismic demands can be estimated by the nonlinear response history analysis (NRHA) of structures to recorded earthquake accelerations, or by nonlinear static analysis - the pushover analysis. However, earthquakes are stochastic and their characteristics differ from one to another. Therefore, the NRHA must be completed using data from more representative earthquakes before structures can be qualified for safety. The NRHA is a reliable method, but tedious and time-consuming. The pushover method is simple and direct. However, this method also has shortcomings. Estimates made using this method are often biased when higher mode effects are pronounced [11, 17].

In the design phase, the estimation of deformation demands for performance assessment can be extremely time-consuming because of the iterative procedures required to properly size the structural members. To help engineers in the preliminary design stage, Gupta \& Krawinkler [7, 9, 16] have proposed a procedure to estimate the roof drift, and the maximum inter-story drift, for GMRF structures. The procedure uses the median spectral displacement at the first period of the structure, with some modification factors. However, it does not account for the dispersion of spectral displacements generated by different earthquakes, hence, the procedure they proposed can only predict the median roof and inter-story drifts, which can easily be exceeded; with a probability of $50 \%$. Therefore, 


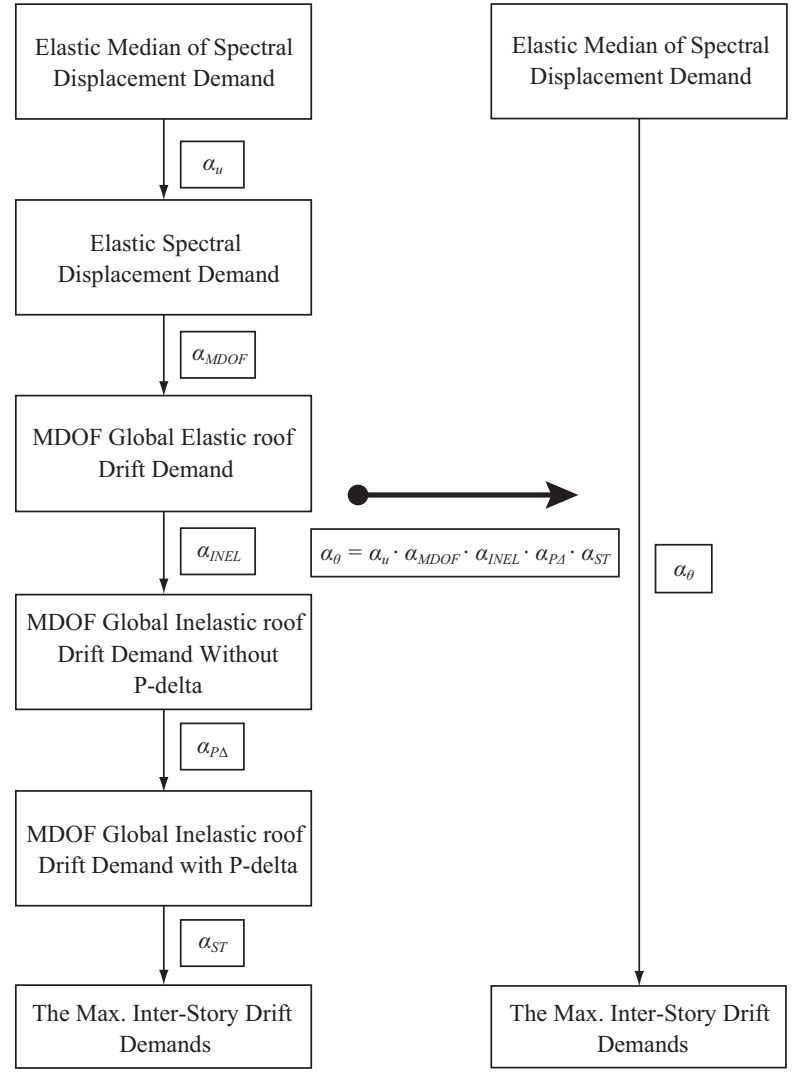

Fig. 1. Process for estimating seismic demands.

improving on Gupta \& Krawinkler's procedure, this study will consider the dispersion of spectral displacement as an important factor in the evaluation of the maximum seismic demands (Fig. 1). Based on probability theory [3], statistical equations will be given in an attempt to provide structural designers with a rapid procedure for evaluating the maximum inter-story drift for both analysis and design.

\section{MODIFICATION FACTORS}

The following modification factors are used in this study:

1. Spectral displacement modification factor $\alpha_{u}$ represents the ratio of $u_{i}$ to the median of all $u_{i}$, where $u_{i}$ is the elastic spectral displacement of a single-degree-of freedom structure to the ith earthquake.

2. Elastic roof displacement modification factor $\alpha_{M D O F}$ is the ratio of the elastic roof displacement demand of a MDOF structure to the spectral displacement $u_{i}$ at the first period of the structure, neglecting $p$-delta effects.

3. Inelastic modification factor $\alpha_{I N E L}$ relates the elastic roof drift demand to the inelastic roof drift demand, neglecting $p$-delta effects.

4. $P$-delta modification factor $\alpha_{P \Delta}$ is the ratio of the inelastic roof displacement, with considering $p$-delta effects, to inelastic roof displacement without considering p-delta effects.
Table 1. The fundamental periods and participation factors of buildings at different distances, from Chelungpu Fault.

\begin{tabular}{|c|c|c|c|}
\hline $\begin{array}{c}\text { Classified } \\
\text { distance } \\
\text { condition }\end{array}$ & $\begin{array}{c}\text { Building } \\
\text { Height } \\
\text { (stories) }\end{array}$ & $\begin{array}{c}\text { 1st-mode period } \\
T_{1}(\mathrm{sec})\end{array}$ & $\begin{array}{c}\text { Participation factor } \\
\text { of the } 1^{\text {st }} \text { mode } \Gamma_{1}\end{array}$ \\
\hline \multirow{2}{*}{$\begin{array}{c}\text { Model } 1 \\
r \leqq 2 \mathrm{~km}\end{array}$} & 5 & 1.16 & 1.35 \\
\cline { 2 - 4 } & 10 & 2.10 & 1.39 \\
\hline \multirow{2}{*}{$\begin{array}{c}\text { Model } 2 \\
2 \mathrm{~km}< \\
r \leqq 5 \mathrm{~km}\end{array}$} & 20 & 3.82 & 1.44 \\
\cline { 2 - 4 } & 5 & 1.18 & 1.35 \\
\hline $\begin{array}{c}\text { Model } 3 \\
5 \mathrm{~km}<\end{array}$ & 20 & 2.10 & 1.39 \\
\cline { 2 - 4 }$r \leqq 8 \mathrm{~km}$ & 20 & 3.88 & 1.44 \\
\hline \multirow{2}{*}{\begin{tabular}{c} 
Model 4 \\
$8 \mathrm{~km}<$ \\
\cline { 2 - 4 }
\end{tabular}} & 5 & 1.19 & 1.36 \\
\cline { 2 - 4 } & 10 & 2.16 & 1.38 \\
\hline
\end{tabular}

Table 2. Structural models and earthquakes near Chelungpu-fault.

\begin{tabular}{|c|c|c|c|c|}
\hline Site & $r \leqq 2 \mathrm{~km}$ & $2 \mathrm{~km}<r \leqq 5 \mathrm{~km}$ & $5 \mathrm{~km}<r \leqq 8 \mathrm{~km}$ & $8 \mathrm{~km}<r \leqq 12 \mathrm{~km}$ \\
\hline Model & Model 1 & Model 2 & Model 3 & Model 4 \\
\hline \multirow{5}{*}{ Earthquakes } & TCU 052 & TCU 054 & TCU 053 & TCU 072 \\
\cline { 2 - 5 } & TCU 067 & TCU 065 & TCU 071 & TCU 089 \\
\cline { 2 - 5 } & TCU 068 & TCU 082 & TCU 075 & TCU 120 \\
\cline { 2 - 5 } & TCU 102 & TCU 129 & TCU 076 & TCU 122 \\
\hline
\end{tabular}

$r$ : distance from Chelungpu fault

5. Story drift modification factor $\alpha_{S T}$ relates the maximum inter-story drift demand to the roof drift demand of a GMRF structure, considering $p$-delta effects.

6. Product modification factor $\alpha_{\theta}$ is the product of the previously defined five modification factors.

$$
\alpha_{\theta}=\alpha_{u} \cdot \alpha_{M D O F} \cdot \alpha_{I N E L} \cdot \alpha_{P \Delta} \cdot \alpha_{S T}
$$

The medians of $\alpha_{u}, \alpha_{M D O F}, \alpha_{I N E L}, \alpha_{P \Delta}, \alpha_{S T}$ and $\alpha_{\theta}$ are denoted by $\hat{\alpha}_{u}, \hat{\alpha}_{M D O F}, \hat{\alpha}_{I N E L}, \hat{\alpha}_{P \Delta}, \hat{\alpha}_{S T}$ and $\hat{\alpha}_{\theta}$, and their dispersions are represented by $\delta_{u}, \delta_{M D O F}, \delta_{I N E L}, \delta_{P \Delta}, \delta_{S T}$ and $\delta_{\theta}$.

\section{STRUCTURAL SYSTEMS}

Four models (Table 2) of strong-column/weak-beam moment-resisting frames of the same height were designed in compliance with Taiwan's steel structural design specifications $[14,15]$. The frames had 5, 10, or 20 stories. Optimal member sections (WF section) of structures were selected automatically with the aid of SAP2000 software [19]. The structures considered are single bay, $7 \mathrm{~m}$ by $7 \mathrm{~m}$ in the horizontal plan, $4 \mathrm{~m}$ high for the first story, and $3.2 \mathrm{~m}$ for the other 
stories. The mass, considered from dead load and 1/4 of live load, is $1784 \mathrm{kgf}$ at the roof level and $2354 \mathrm{kgf}$ for the other stories. Table 1 shows the fundamental periods and the first modal participation factors of the designed frames. In nonlinear analyses, the program DRAIN-2D+ [18] was used to perform dynamic and static analyses. Plastic hinges, which had 2 percent strain hardening in bilinear models of momentrotation relationships, were assigned at column bases and beam-ends. The form of the Rayleigh damping matrix is considered to be $C=\alpha M+\beta K$. The $\alpha$ and $\beta$ factors are computed to satisfy a damping ratio of 5 percent for both the first and second modes.

\section{EARTHQUAKE DATA}

Sixteen Chi-Chi earthquake data sets near-Chelungpu-fault (Table 2) were used in this study. Nonlinear inelastic simulations of the structures' responses have been conducted for both the life safety performance level $(0.33 \mathrm{~g})$ and the collapse prevention level $(0.4 \mathrm{~g})$. The ground accelerations were adjusted by near-fault factors $N_{A}, N_{V}$ (Table 3 ). Figure 2 shows the elastic spectral acceleration/PGA diagrams for $\mathrm{PGA}=0.33$ g. The median curve in the figure was obtained using (2),

$$
\hat{x}=\exp \left[\frac{\sum_{i=1}^{n} \ln x_{i}}{n}\right]
$$

Where $x_{i}$ is the individual sample value, $\hat{x}$ is the median value of the sample, and $n$ is the size of the sample ( $n=16$ in this study, 4 earthquakes for each of 4 models of structure).

\section{ANALYSIS PROCEDURE}

The analysis procedure can be briefly described as follows:

(a) Design code-compliant structural models for different distances from the Chelungpu fault.

(b) Determine the elastic spectral displacement $u_{i}$ of the SDOF system subjected to an individual earthquake. The $u_{i}$ of the collapse prevention level can be scaled up from the $u_{i}$ of the life safety performance level by a factor of $0.4 \mathrm{~g} / 0.33 \mathrm{~g}$.

(c) Determine the median of $u_{i}$, denoted by $\hat{u}$.

(d) Conduct the elastic response history analyses for the buildings to each of the Chi-Chi earthquakes specified in Table 2; find the maximum roof displacements in each case using DRAIN2D+.

(e) Conduct non-linear response history analyses for the buildings for the same earthquake records, and find the maximum roof displacements and story drift angles in each case (without the P-delta effect).

(f) Perform the same analyses as in step (e) considering the P-delta effect. In other words, consider the geometric stiffness in these analyses.
Table 3. Near-Fault factors $N_{A}, N_{V}$ for Chelungpu fault.

(a) Adjustment factors for design force

\begin{tabular}{|c|c|c|c|c|}
\hline \multirow{2}{*}{$N_{A}$} & $r \leqq 2 \mathrm{~km}$ & $2 \mathrm{~km}<r \leqq 5 \mathrm{~km}$ & $5 \mathrm{~km}<r \leqq 8 \mathrm{~km}$ & $8 \mathrm{~km}<r \leqq 12 \mathrm{~km}$ \\
\cline { 2 - 5 } & 1.23 & 1.16 & 1.07 & 1.03 \\
\hline \multirow{2}{*}{$N_{V}$} & $r \leqq 2 \mathrm{~km}$ & $2 \mathrm{~km}<r \leqq 5 \mathrm{~km}$ & $5 \mathrm{~km}<r \leqq 8 \mathrm{~km}$ & $8 \mathrm{~km}<r \leqq 12 \mathrm{~km}$ \\
\cline { 2 - 5 } & 1.36 & 1.32 & 1.22 & 1.10 \\
\hline
\end{tabular}

(b) The maximum adjustment factors for design force

\begin{tabular}{|c|c|c|c|c|}
\hline \multirow{2}{*}{$N_{A}$} & $r \leqq 2 \mathrm{~km}$ & $2 \mathrm{~km}<r \leqq 5 \mathrm{~km}$ & $5 \mathrm{~km}<r \leqq 8 \mathrm{~km}$ & $8 \mathrm{~km}<r \leqq 12 \mathrm{~km}$ \\
\cline { 2 - 5 } & 1.25 & 1.20 & 1.10 & 1.03 \\
\hline \multirow{2}{*}{$N_{V}$} & $r \leqq 2 \mathrm{~km}$ & $2 \mathrm{~km}<r \leqq 5 \mathrm{~km}$ & $5 \mathrm{~km}<r \leqq 8 \mathrm{~km}$ & $8 \mathrm{~km}<r \leqq 12 \mathrm{~km}$ \\
\cline { 2 - 5 } & 1.50 & 1.45 & 1.30 & 1.15 \\
\hline
\end{tabular}

$r$ : distance from Chelungpu fault

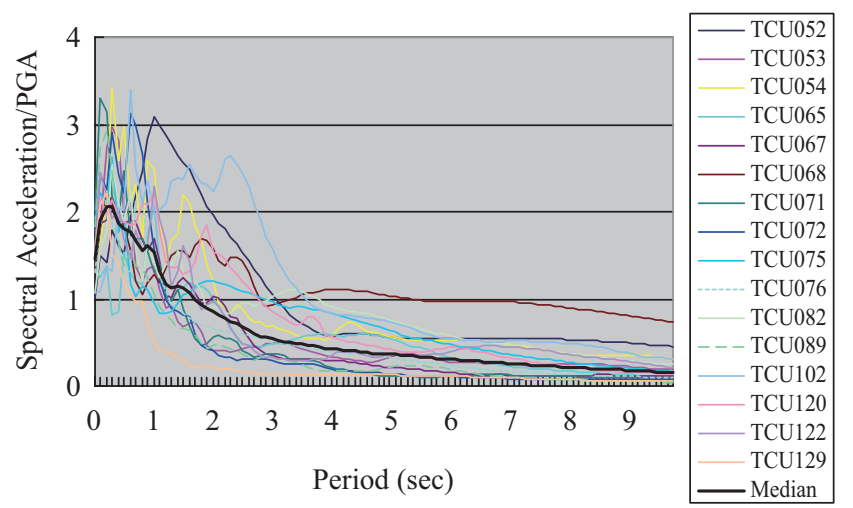

Fig. 2. The normalized pseudo-acceleration response spectra of near Chelungpu fault, PGA = $0.33 \mathrm{~g}$.

(g) Calculate a set of modification factors $\alpha_{u}, \alpha_{M D O F}, \alpha_{I N E L}$, $\alpha_{P \Delta}, \alpha_{S T}$ for each structure, relevant to each individual earthquake record. Also evaluate their medians and dispersions using (2) and (3) respectively.

$$
\delta=\left[\frac{\sum_{i=1}^{n}\left(\ln x_{i}-\ln \hat{x}\right)^{2}}{n-1}\right]^{1 / 2}
$$

Where $\delta=$ the dispersion of a sample

$$
\begin{aligned}
x_{i} & =\text { the individual sample value } \\
\hat{x} & =\text { the median value of a sample } \\
n & =\text { the sample size }(n=16, \text { same as that in }(2))
\end{aligned}
$$

(h) Calculate the median of $\alpha_{\theta}$ using (4).

$$
\hat{\alpha}_{\theta}=\hat{\alpha}_{u} \cdot \hat{\alpha}_{M D O F} \cdot \hat{\alpha}_{I N E L} \cdot \hat{\alpha}_{P \Delta} \cdot \hat{\alpha}_{S T}
$$

The derivation of (4) is shown in Appendix A.

(i) Calculate the dispersion of $\alpha_{\theta}$ directly by (3) or indirectly by (5). 


$$
\begin{aligned}
\delta_{\theta}^{2}= & \delta_{u}^{2}+\delta_{M D O F}^{2}+\delta_{I N E L}^{2}+\delta_{P \Delta}^{2}+\delta_{S T}^{2}+2\left(\delta_{u, M D O F}+\delta_{u, I N E L}\right. \\
& +\delta_{u, P \Delta}+\delta_{u, S T}+\delta_{M D O F, I N E L}+\delta_{M D O F, P \Delta}+\delta_{M D O F, S T} \\
& \left.+\delta_{I N E L, P \Delta}+\delta_{I N E L, S T}+\delta_{P \Delta, S T}\right)
\end{aligned}
$$

Where $\delta_{u}^{2}, \delta_{M D O F}^{2}, \delta_{I N E L}^{2}, \delta_{P \Delta}^{2}, \delta_{S T}^{2}$ are variances and $\delta_{u, M D O F}$, $\delta_{u, I N E L}, \delta_{u, P \Delta}, \delta_{u, S T}, \delta_{M D O F, I N E L}, \delta_{M D O F, P \Delta,} \delta_{M D O F, S T} \delta_{I N E L, P \Delta,}$ $\delta_{I N E L, S T}$, and $\delta_{P \triangle, S T}$ are co-variances of the modification factors. The derivation of (5) is given in Appendix A.

(j) Calculate the maximum inter-story drift ratio using (6), (7), or (8), corresponding to a confidence level of $50 \%$, $84.14 \%$, or $97.73 \%$.

$$
\begin{gathered}
\theta_{\max , 50 \%}=\hat{\alpha}_{\theta} \frac{\hat{u}}{H} \\
\theta_{\text {max,84.14\% }}=\exp \left(\ln \hat{\alpha}_{\theta}+\delta_{\theta}\right) \frac{\hat{u}}{H} \\
\theta_{\text {max }, 97.73 \%}=\exp \left(\ln \hat{\alpha}_{\theta}+2 \delta_{\theta}\right) \frac{\hat{u}}{H}
\end{gathered}
$$

Where $\hat{u}$ is the median of elastic spectral displacement and $H$ is the height of the structure. Depending on the importance of the structure, one may choose to use (6), (7), or (8).

\section{DISCUSSION OF RESULTS}

The calculated median and dispersion values of $\alpha_{u}, \alpha_{M D O F}$, $\alpha_{I N E L}, \alpha_{P \Delta}, \alpha_{S T}$, and $\alpha_{\theta}$ are shown in Tables 4-5 and 7-10. The following observations can be made from the results.

(a) As shown in Table 4, the medians $\hat{\alpha}_{u}$ are approximately 1.0 for both life safety performance level and collapse prevention level, regardless of structural height. This result is reasonable, since the evaluation is starting from the median value of elastic spectral displacement at the first period of the structure. Due to the great randomness of near fault earthquakes, the dispersions of $\alpha_{u}$ (between 0.43 and 0.65 ) are relatively larger than the dispersions of other modification factors. Hence, $\delta_{\theta}$ in (5) is dominated by $\delta_{u}$ and, in turn, $\delta_{u}$ is very influential in determining the maximum inter-story drift ratio by (6), (7), and (8).

(b) The median values, $\hat{\alpha}_{M D O F}$, (Table 5) of 5 and 10-story buildings are approximately equal to $\Gamma_{1}-$ the participation factor of the first mode, while the values of 20-story building are greater than $\Gamma_{1}$, implying that, only for taller buildings, the higher modes have more effect on $\hat{\alpha}_{M D O F}$. Table 6 shows the ratio of $\hat{\alpha}_{M D O F}$ to the participation factor $\Gamma_{1}$.
Table 4. Median and dispersion of $\alpha_{u}$.

\begin{tabular}{|c|c|c|c|c|c|c|}
\hline $\begin{array}{c}\text { Seismic } \\
\text { levels }\end{array}$ & \multicolumn{3}{|c|}{ Life safety performance level } & \multicolumn{3}{|c|}{ Collapse prevention level } \\
\hline Story No & $5 \mathrm{~F}$ & $10 \mathrm{~F}$ & $20 \mathrm{~F}$ & $5 \mathrm{~F}$ & $10 \mathrm{~F}$ & $20 \mathrm{~F}$ \\
\hline Median & 1.01 & 0.98 & 1.00 & 1.03 & 1.03 & 1.02 \\
\hline Dispersion & 0.44 & 0.65 & 0.64 & 0.43 & 0.65 & 0.64 \\
\hline
\end{tabular}

Table 5. Median and dispersion of $\alpha_{M D O F}$.

\begin{tabular}{|c|c|c|c|c|c|c|}
\hline $\begin{array}{c}\text { Seismic } \\
\text { levels }\end{array}$ & \multicolumn{3}{|c|}{ Life safety performance level } & \multicolumn{3}{|c|}{ Collapse prevention level } \\
\hline Story No & $5 \mathrm{~F}$ & $10 \mathrm{~F}$ & $20 \mathrm{~F}$ & $5 \mathrm{~F}$ & $10 \mathrm{~F}$ & $20 \mathrm{~F}$ \\
\hline Median & 1.35 & 1.34 & 1.68 & 1.35 & 1.34 & 1.68 \\
\hline Dispersion & 0.14 & 0.36 & 0.29 & 0.14 & 0.36 & 0.29 \\
\hline
\end{tabular}

Table 6. Ratio of the modification factor $\alpha_{M D O F}$ to participation factor $\Gamma_{1}$.

\begin{tabular}{|c|c|c|c|c|c|c|}
\hline $\begin{array}{c}\text { Seismic } \\
\text { levels }\end{array}$ & \multicolumn{2}{|c|}{ Life safety performance level } & \multicolumn{3}{|c|}{ Collapse prevention level } \\
\hline Story No. & $5 \mathrm{~F}$ & $10 \mathrm{~F}$ & $20 \mathrm{~F}$ & $5 \mathrm{~F}$ & $10 \mathrm{~F}$ & $20 \mathrm{~F}$ \\
\hline Model & 0.97 & 1.02 & 1.14 & 0.97 & 1.02 & 1.14 \\
\hline $\begin{array}{c}\text { Model 1 } \\
r \leqq 2 \mathrm{~km}\end{array}$ & 0.98 & 1.03 & 1.02 & 0.98 & 1.03 & 1.02 \\
\hline $\begin{array}{c}\text { Model 2 } \\
2 \mathrm{~km}< \\
r \leqq 5 \mathrm{~km}\end{array}$ & 1.08 & 0.97 & 1.14 & 1.08 & 0.97 & 1.14 \\
\hline $\begin{array}{c}\text { Model 3 } \\
5 \mathrm{~km}< \\
r \leqq 8 \mathrm{~km}\end{array}$ & 0.97 & 0.86 & 1.38 & 0.97 & 0.87 & 1.38 \\
\hline $\begin{array}{c}\text { Model } 4 \\
8 \mathrm{~km}< \\
r \leqq 12 \mathrm{~km}\end{array}$ & & & & & & \\
\hline
\end{tabular}

Table 7. Median and dispersion of $\alpha_{I N E L}$.

\begin{tabular}{|c|c|c|c|c|c|c|}
\hline Seismic levels & \multicolumn{3}{|c|}{ Life safety performance level } & \multicolumn{3}{|c|}{ Collapse prevention level } \\
\hline Story No & $5 \mathrm{~F}$ & $10 \mathrm{~F}$ & $20 \mathrm{~F}$ & $5 \mathrm{~F}$ & $10 \mathrm{~F}$ & $20 \mathrm{~F}$ \\
\hline Median & 0.97 & 0.93 & 0.88 & 0.93 & 0.91 & 0.87 \\
\hline Dispersion & 0.18 & 0.16 & 0.17 & 0.23 & 0.19 & 0.16 \\
\hline
\end{tabular}

Table 8. Median and dispersion of $\alpha_{P \Delta}$.

\begin{tabular}{|c|c|c|c|c|c|c|}
\hline Seismic levels & \multicolumn{3}{|c|}{ Life safety performance level } & \multicolumn{4}{|c|}{ Collapse prevention level } \\
\hline Story No & $5 \mathrm{~F}$ & $10 \mathrm{~F}$ & $20 \mathrm{~F}$ & $5 \mathrm{~F}$ & $10 \mathrm{~F}$ & $20 \mathrm{~F}$ \\
\hline Median & 1.00 & 1.02 & 1.06 & 1.01 & 1.03 & 1.11 \\
\hline Dispersion & 0.04 & 0.04 & 0.15 & 0.05 & 0.10 & 0.19 \\
\hline
\end{tabular}

(c) The statistics of the inelastic modification factor, $\hat{\alpha}_{I N E L}$, are given in Table 7. The medians are clearly less than 1.0 (0.87 0.97), having no conspicuous correlation with earthquake intensity and structural height. This phenome- 
Table 9. Median and dispersion of $\alpha_{S T}$.

\begin{tabular}{|c|c|c|c|c|c|c|}
\hline Seismic levels & \multicolumn{2}{|c|}{ Life safety performance level } & \multicolumn{4}{|c|}{ Collapse prevention level } \\
\hline Story No & $5 \mathrm{~F}$ & $10 \mathrm{~F}$ & $20 \mathrm{~F}$ & $5 \mathrm{~F}$ & $10 \mathrm{~F}$ & $20 \mathrm{~F}$ \\
\hline Median & 1.35 & 1.52 & 1.81 & 1.40 & 1.61 & 1.99 \\
\hline Dispersion & 0.09 & 0.12 & 0.17 & 0.10 & 0.13 & 0.17 \\
\hline
\end{tabular}

Table 10. Median and dispersion of $\alpha_{\theta}$.

\begin{tabular}{|c|c|c|c|c|c|c|}
\hline Seismic levels & \multicolumn{3}{|c|}{ Life safety performance level } & \multicolumn{4}{|c|}{ Collapse prevention level } \\
\hline Story No & $5 \mathrm{~F}$ & $10 \mathrm{~F}$ & $20 \mathrm{~F}$ & $5 \mathrm{~F}$ & $10 \mathrm{~F}$ & $20 \mathrm{~F}$ \\
\hline Median & 1.77 & 1.91 & 2.81 & 1.84 & 2.07 & 3.26 \\
\hline Dispersion & 0.50 & 0.59 & 0.50 & 0.55 & 0.71 & 0.68 \\
\hline
\end{tabular}

non can be attributed to the hysteretic dissipation of energy. The dispersions are also satisfactorily less than 0.23 .

(d) The $p$-delta factor, $\hat{\alpha}_{P \Delta}$, which is defined as the ratio of roof displacements with and without $p$-delta effects, is presented in Table 8 . $P$-delta always reduces the effective stiffness and thus increases the roof displacements. Detailed study of $p$-delta effects in reference [8] concludes that $p$-delta is a relatively benign phenomenon, unless the ground motion drives the structure into the range of negative post-yield stiffness. This conclusion is also supported by the results of this study, as shown in Table 8all medians are between 1.0 and 1.11, and dispersions are not greater than 0.19 .

(e) The statistical measurements of story drift modification factor $\hat{\alpha}_{S T}$, which relate the maximum inter-story drift demand over the height of the structure to the roof drift demand, and which consider the $p$-delta effect, are given in Table 9. The medians range from 1.35 to 1.99 , depending on the number of stories and the earthquake intensity. It can be seen from Table 9 that, taller buildings increase the effects on both median and dispersion. In general, the earthquake intensity has a weakly increasing effect on the median of this factor. The medians $\hat{\alpha}_{S T}$ is in such a narrow range because the structural members are optimally selected by computer program i.e. SAP2000. Member sizes gradually change along the height of the structure.

(f) The medians and dispersions of structures for all models pertaining to the same height are given in Table 10. The medians $\left(\hat{\alpha}_{\theta}\right)$ are in a narrow range between 1.77 and 3.26 , varying increasingly with the number of stories, but indifferent to earthquake intensity. The dispersions $\delta_{\theta}$ are greater than 0.5 . Table 11 is given as an example to show the components of $\delta_{\theta}^{2}$ Eq. (5), in which $\delta_{u}^{2}$ is the largest contributor among all components. Qualitative comparison of medians and dispersions for each of the four models is given in Figs. 3 and 4. It can be seen that,
Table 11. The co-variances of logarithms of $\alpha_{u}, \alpha_{M D O F}$, $\alpha_{I N E L}, \alpha_{P \Delta} \& \alpha_{S T}$ in $\delta_{\theta}^{2}$.

\begin{tabular}{|c|c|c|}
\hline 5-story buildings & \multicolumn{2}{|c|}{ Chelungpu fault } \\
\hline Co-variances & Life safety level & Collapse prevention level \\
\hline$\delta_{u}^{2}$ & $189.47 \mathrm{E}-03$ & $186.75 \mathrm{E}-03$ \\
\hline$\delta_{M D O F}^{2}$ & $20.82 \mathrm{E}-03$ & $20.51 \mathrm{E}-03$ \\
\hline$\delta_{I N E L}^{2}$ & $32.62 \mathrm{E}-03$ & $51.96 \mathrm{E}-03$ \\
\hline$\delta_{P \Delta}^{2}$ & $1.66 \mathrm{E}-03$ & $2.11 \mathrm{E}-03$ \\
\hline$\delta_{S T}^{2}$ & $8.81 \mathrm{E}-03$ & $10.61 \mathrm{E}-03$ \\
\hline$\delta_{u, \mathrm{MDOF}}$ & $-22.1 \mathrm{E}-03$ & $-22.03 \mathrm{E}-03$ \\
\hline$\delta_{u, \text { INEL }}$ & $-24.9 \mathrm{E}-03$ & $-23.33 \mathrm{E}-03$ \\
\hline$\delta_{u, \mathrm{P} \Delta}$ & $-2.00 \mathrm{E}-03$ & $5.44 \mathrm{E}-03$ \\
\hline$\delta_{u, \mathrm{ST}}$ & $20.5 \mathrm{E}-03$ & $22.23 \mathrm{E}-03$ \\
\hline$\delta_{M D O F, I N E L}$ & $2.09 \mathrm{E}-03$ & $-0.86 \mathrm{E}-03$ \\
\hline$\delta_{M D O F, P \Delta}$ & $0.87 \mathrm{E}-03$ & $0.22 \mathrm{E}-03$ \\
\hline$\delta_{M D O F, S T}$ & $-2.59 \mathrm{E}-03$ & $-1.63 \mathrm{E}-03$ \\
\hline$\delta_{I N E L, P \Delta}$ & $6.14 \mathrm{E}-03$ & $4.51 \mathrm{E}-03$ \\
\hline$\delta_{I N E L, \mathrm{ST}}$ & $6.97 \mathrm{E}-03$ & $14.32 \mathrm{E}-03$ \\
\hline$\delta_{P \triangle, S T}$ & $1.64 \mathrm{E}-03$ & $2.99 \mathrm{E}-03$ \\
\hline
\end{tabular}

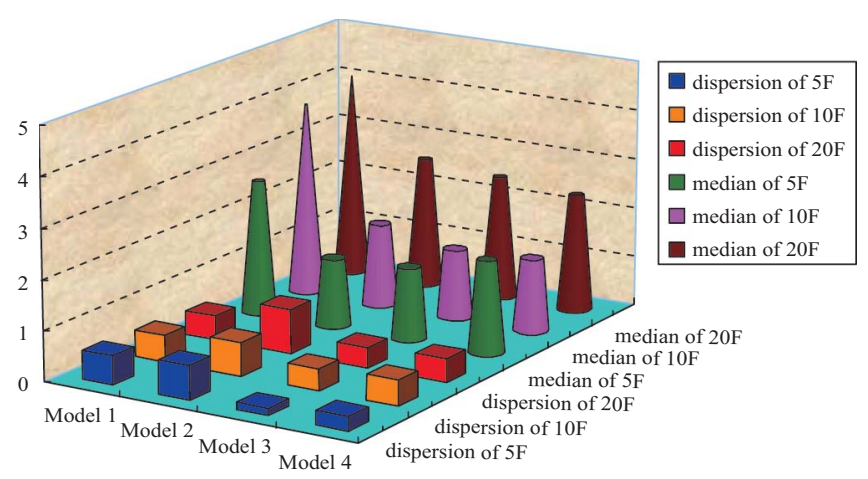

Fig. 3. Statistics of the modification factor $\alpha_{\theta}$ for buildings different distance from the fault (life safety performance level)

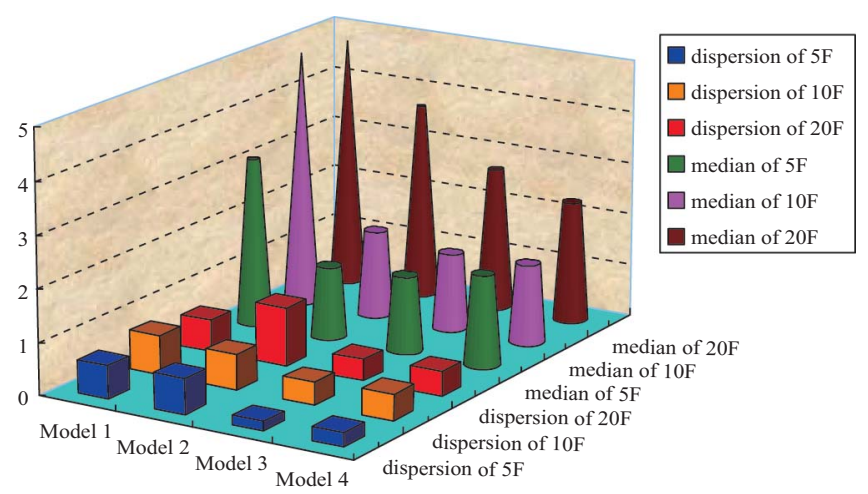

Fig. 4. Statistics of the modification factor $\alpha_{\theta}$ for buildings different distance from the fault (collapse prevention level). 


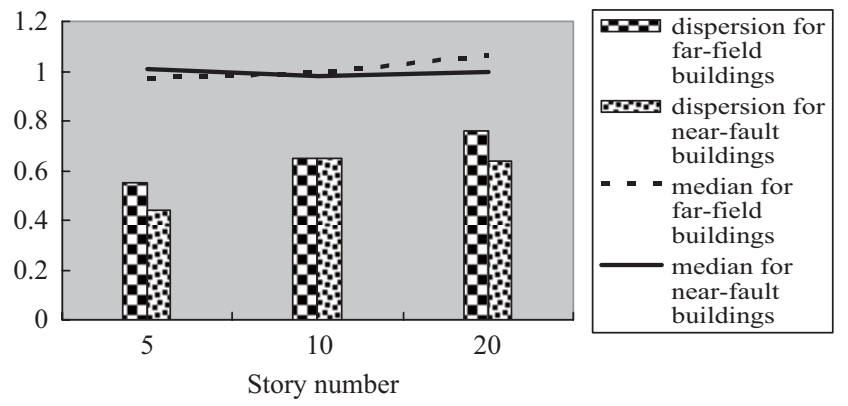

Fig. 5. Comparison of the modification factor $\alpha_{u}$ between near-fault and far-field buildings (life safety performance level).

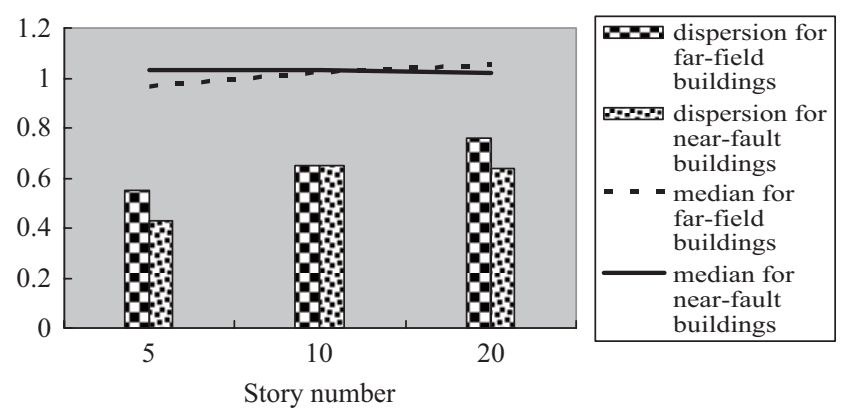

Fig. 6. Comparison of the modification factor $\alpha_{u}$ between near-fault and far-field buildings (collapse prevention level).

despite of the performance level, the medians of model 1 $(0<r<2 \mathrm{~km})$ are much greater than those of the other models. This phenomenon reflects that the displacement and impulse are relatively large in this region and care must be taken for structures being designed in this region.

\section{COMPARISON OF MODIFICATION FACTORS FOR STEEL GMRF STRUCTURES IN NEAR-FAULT AND FAR-FIELD REGIONS}

The medians and dispersions of modification factors obtained in this study are compared with those in Reference [12] by the authors, for both life safety and collapse prevention levels. Some important results are given as follows:

(a) As shown in Figs. 5 and 6, the medians of $\hat{\alpha}_{u}$ are matching well for structures in both regions. However, the dispersions of near-fault buildings are slightly smaller than, those of buildings in the far-field regions.

(b) The comparison of $\hat{\alpha}_{M D O F}$ are shown in Figs. 7 and 8. The medians of near-fault region are less than that of far-field region for 5 and 10- story buildings, but greater than that of far-field region for 20 -story buildings. The dispersions are, in general, greater for near-fault buildings in comparison with that of far-field buildings.

(c) The medians of $\hat{\alpha}_{I N E L}$ (Figs. 9 and 10) are slightly increasing with the story height for the far-field buildings, but are slightly decreasing with the story height for the

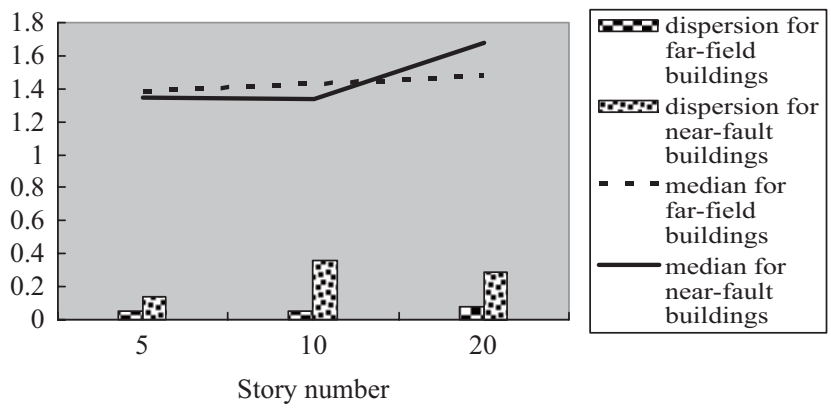

Fig. 7. Comparison of the modification factor $\boldsymbol{\alpha}_{M D O F}$ between near-fault and far-field buildings (life safety performance level).

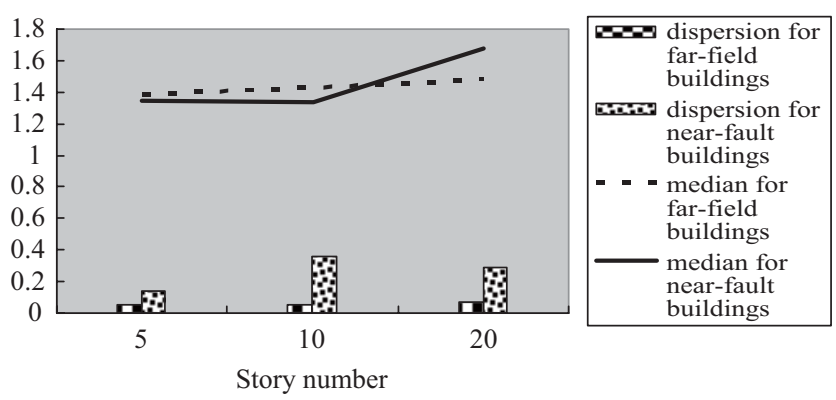

Fig. 8. Comparison of the modification factor $\alpha_{M D O F}$ between near-fault and far-field buildings (collapse prevention level).

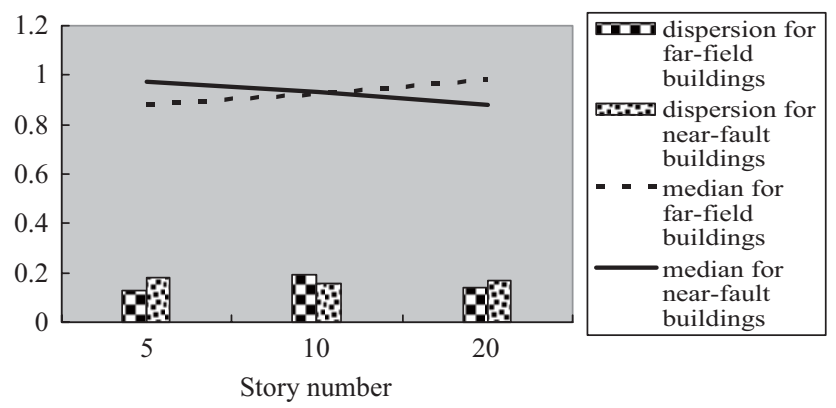

Fig. 9. Comparison of the modification factor $\alpha_{I N E L}$ between near-fault and far-field buildings (life safety performance level).

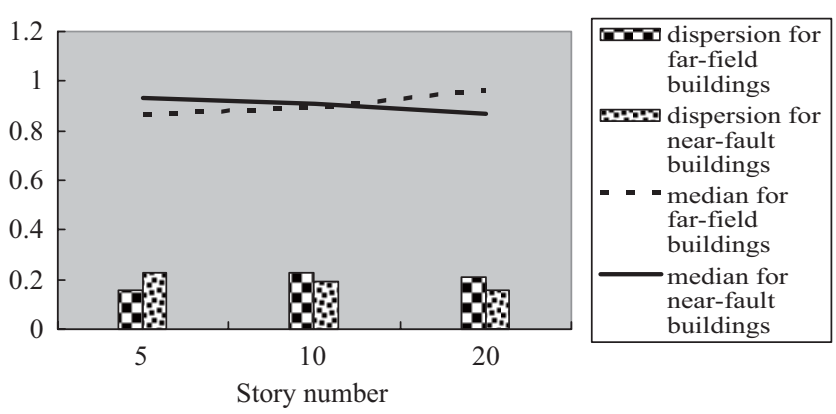

Fig. 10. Comparison of the modification factor $\alpha_{I N E L}$ between near-fault and far-field buildings (collapse prevention level).

near-fault buildings. The dispersions are small for buildings in both regions. 


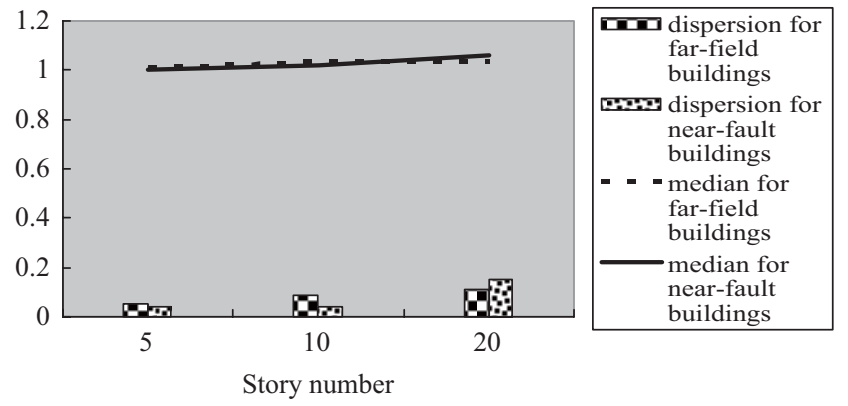

Fig. 11. Comparison of the modification factor $\alpha_{P \Delta}$ between near-fault and far-field buildings (life safety performance level).

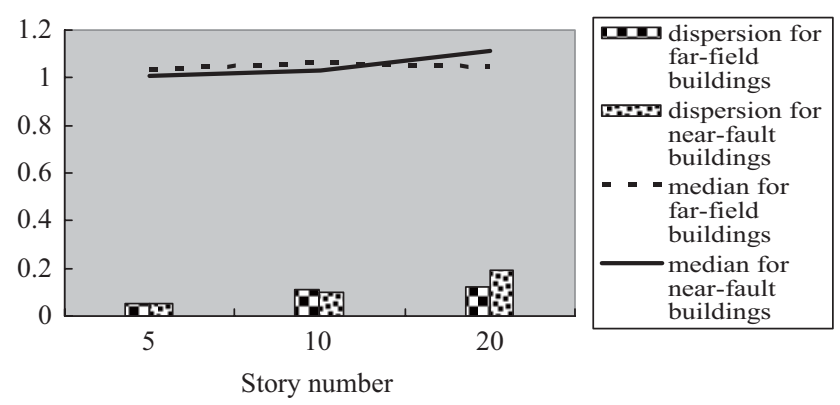

Fig. 12. Comparison of the modification factor $\alpha_{P \Delta}$ between near-fault and far-field buildings (collapse prevention level).

(d) The medians of $\hat{\alpha}_{P \Delta}$ (Figs. 11 and 12) are matching well for buildings in both regions. The dispersions are also small for buildings in both regions.

(e) The medians of $\hat{\alpha}_{S T}$ (Figs. 13 and 14) have a tendency of increasing with the story height for buildings in both regions and are not much different from each other. The dispersions are also small for buildings in both regions.

(f) For both regions, the medians of $\hat{\alpha}_{\theta}$ (Figs. 15 and 16) are increasing with the story height and in a narrow range between 1.6 and 3.3. The dispersions are less than 0.78 .

\section{APPLICATION}

Referring to the analysis results presented in Table 10, engineers can rapidly evaluate the maximum inter-story drift ratio of an existing structure using (6), (7), and (8), for any desired confidence probability. Application of this evaluation can also be extended to the design of a new GMRF structure. In order to meet the design requirements; the structural height, number of stories, generic dead and live loads, and the performance levels of earthquake force for a specified earthquake region and soil condition, the following story-drift-ratio-based design procedure is suggested:

\section{Design Procedure for a GMRF Structure}

(1) Design a new GMRF structure to meet the design requirements, using software such as SAP 2000, which allows selection of optimal structural elements.

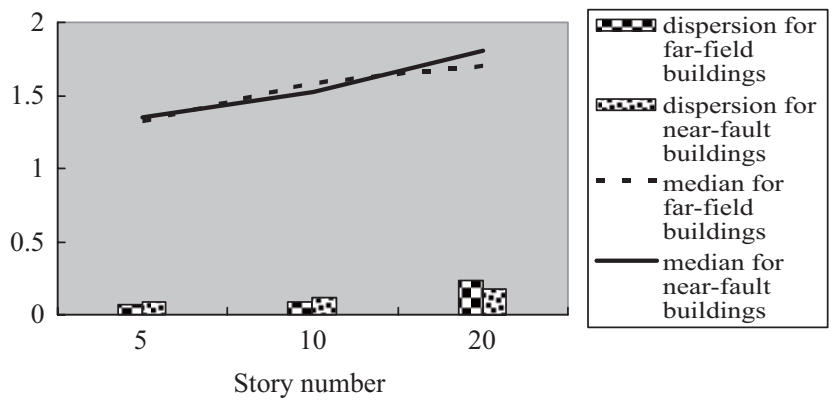

Fig. 13. Comparison of the modification factor $\alpha_{S T}$ between near-fault and far-field buildings (life safety performance level).

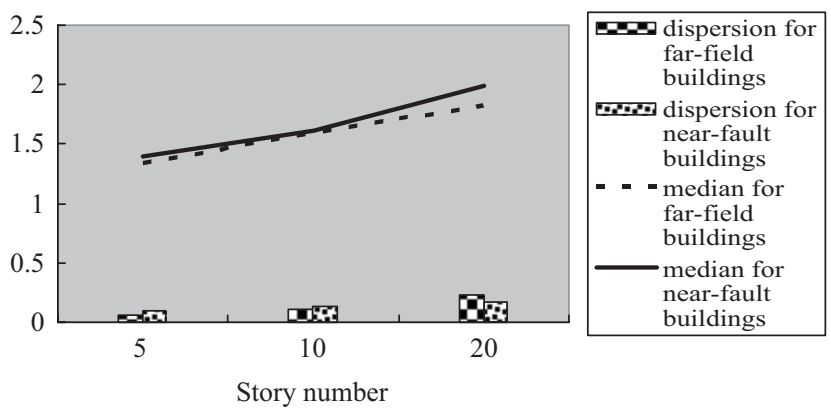

Fig. 14. Comparison of the modification factor $\alpha_{S T}$ between near-fault and far-field buildings (collapse prevention level).

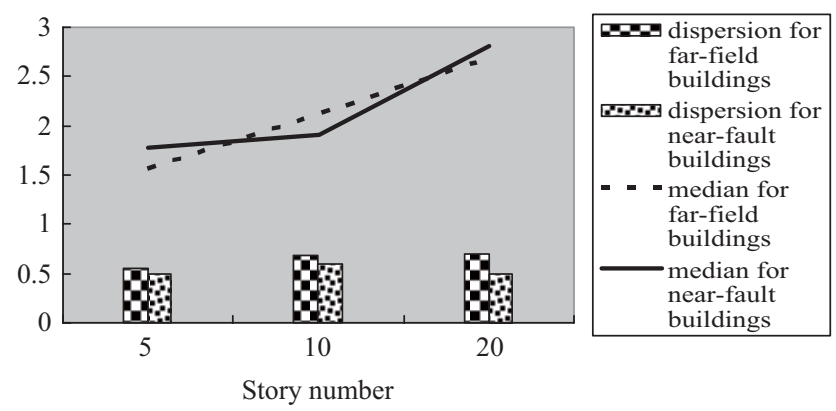

Fig. 15. Comparison of the modification factor $\alpha_{\theta}$ between near-fault and far-field buildings (life safety performance level).

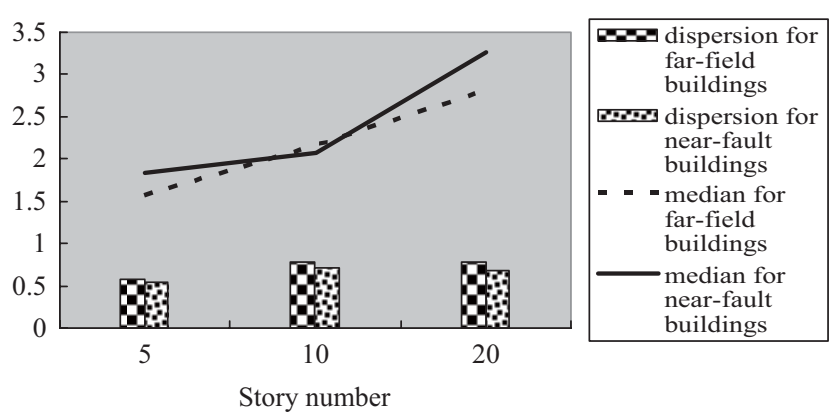

Fig. 16. Comparison of the modification factor $\alpha_{\theta}$ between near-fault and far-field buildings (collapse prevention level).

(2) Calculate the fundamental frequency, $\omega_{1}$ of the newly designed GMRF structure. 
(3) Determine the median of normalized pseudo-acceleration A from the acceleration response spectra shown in Fig. 2 and adjust it for specified seismic performance levels.

(4) Obtain the median of elastic spectral displacement $\hat{u}$ using

$$
\hat{u}=\frac{A}{\omega_{1}^{2}}
$$

(5) Find the median and the dispersion of $\alpha_{\theta}$ from Table 10, (by interpolation if necessary).

(6) Calculate the maximum inter-story drift ratios using (6), (7), or (8) for all specified performance levels, and compare them with the limits specified by FEMA 273. If any one of them exceeds its corresponding limit, then repetition of steps 1 to 6 is required until the maximum inter-story drift ratios for all specified performance levels fall within their limits. Since the medians of model 1 $(0<r<2 \mathrm{~km})$ are much greater than those shown in Table 10 , one is suggested to use (8) when a structure to be designed is less than $2 \mathrm{~km}$ from the fault and if data of $\hat{\alpha}_{\theta}$ and $\delta_{\theta}$ in Table 10 are used.

\section{Design Example}

A 20 story structure, between two to five kilometers from Chelungpu Fault, $4 \mathrm{~m}$ high for the first story and $3.2 \mathrm{~m}$ for the others, is to be designed. The live load is $300 \mathrm{~kg} / \mathrm{m}^{2}$ for all floor levels, and the dead load is $300 \mathrm{~kg} / \mathrm{m}^{2}$ for the roof and $400 \mathrm{~kg} / \mathrm{m}^{2}$ for other floor levels. The structure must satisfy the inter-story drift ratio limits at two hazard levels -0.025 for the life safety level and 0.05 for the collapse prevention level. Consider confidence probability levels of $50 \%$ and $84.14 \%$.

Solution: Equations (6) and (7) can be used to estimate the maximum inter-story drift ratio. The natural period of the preliminarily designed structure is $3.53 \mathrm{sec}\left(\omega_{1}=1.78 \mathrm{rad} / \mathrm{sec}\right)$, the height of the building is $64.8 \mathrm{~m}$.

Life safety level $\left(\ddot{u}_{g 0}=0.33 \mathrm{~g}\right)$

From Fig. 2, $\mathrm{A}=0.484 \ddot{u}_{g 0}, \hat{u}=\frac{A}{\omega_{1}^{2}}=0.49 \mathrm{~m}$.

From Table 10, $\hat{\alpha}_{\theta}=2.81, \delta_{\theta}=0.50$, and by (6) and (7)

$$
\begin{gathered}
\theta_{\max , 50 \%}=\hat{\alpha}_{\theta} \cdot \frac{\hat{u}}{H}=0.021 \leq 0.025 \Rightarrow \mathrm{OK} \\
\theta_{\max , 84.14 \%}=\exp \left(\ln \hat{\alpha}_{\theta}+\delta_{\theta}\right) \frac{\hat{u}}{H}=0.035>0.025
\end{gathered}
$$

It is seen that $\theta_{\max , 84.14 \%}$ exceeds the limit of 0.025 ; redesign is needed. By increasing the base shear of the structure and by iterating steps 1-6 in the design procedure, a new GMRF structure with a fundamental natural period of $2.42 \mathrm{sec}$ $\left(\omega_{1}=2.60 \mathrm{rad} / \mathrm{sec}\right)$ is designed. The member sizes are shown in Appendix B.
From Fig. 2, $\mathrm{A}=0.74 \ddot{u}_{g 0}, \hat{u}=\frac{A}{\omega_{1}^{2}}=0.35 \mathrm{~m}$.

$$
\begin{gathered}
\theta_{\max , 50 \%}=\hat{\alpha}_{\theta} \cdot \frac{\hat{u}}{H}=0.015 \leq 0.025 \Rightarrow \mathrm{OK} \\
\theta_{\max , 84.14 \%}=\exp \left(\ln \hat{\alpha}_{\theta}+\delta_{\theta}\right) \frac{\hat{u}}{H}=0.025 \leq 0.025 \Rightarrow \mathrm{OK}
\end{gathered}
$$

Collapse prevention level $\left(\ddot{u}_{g 0}=0.4 \mathrm{~g}\right)$

$$
\hat{u}=0.35 \mathrm{~m}\left(\frac{0.4 \mathrm{~g}}{0.33 \mathrm{~g}}\right)=0.42 \mathrm{~m}, \hat{\alpha}_{\theta}=3.26, \delta_{\theta}=0.68
$$

(from Table 10)

$$
\begin{gathered}
\text { Similarly } \theta_{\max , 50 \%}=\hat{\alpha}_{\theta} \cdot \frac{\hat{u}}{H}=0.021 \leq 0.05 \Rightarrow \mathrm{OK} \\
\theta_{\max , 84.14 \%}=\exp \left(\ln \hat{\alpha}_{\theta}+\delta_{\theta}\right) \frac{\hat{u}}{H}=0.042 \leq 0.05 \Rightarrow \mathrm{OK}
\end{gathered}
$$

\section{FINDINGS, CONCLUSIONS, AND LIMITATIONS}

This study has conducted research on the modification factors $\alpha_{u}, \alpha_{M D O F}, \alpha_{I N E L}, \alpha_{P \Delta}, \alpha_{S T}$ and $\alpha_{\theta}$ by performing simulations on Taiwan code-compliant steel structures of different heights. Sixteen Chi-Chi earthquake data sets near Chelungpu fault were used for nonlinear time-history analyses. The medians and dispersions of all these modification factors were evaluated. Equations have been established to calculate the maximum inter-story drift demands of steel GMRF structures for any confidence level. The analysis results have shown that all statistical data are steady and reliable, regardless of the number of stories. Therefore, this rapid method for evaluating seismic demands should be acceptable and reliable for both analysis and design, and would be especially valuable during the preliminary design stage.

Among the modification factors, the dispersion of $\alpha_{u}$ is very influential in determining the inter-story drift demand. If the dispersion of $\alpha_{u}$ is excluded, then the dispersion of $\alpha_{\theta}$ will be around 0.3 or less, which means that the lognormal distribution of $\alpha_{\theta}$ will have a normal shape. Unfortunately, in most cases in this study, the dispersions of $\alpha_{\theta}$ are greater than 0.5. Therefore, the distribution of $\alpha_{\theta}$ is lognormal in shape. The comparison of medians and dispersions of modification factors were made for buildings in the near-fault and far-field regions, It is found that the differences of them are small between the two regions. However, care must be taken when buildings to be designed are less than $2 \mathrm{~km}$ from the fault, since the medians $\hat{\alpha}_{\theta}$ of structures in this region are relatively larger than those of the other regions $(2 \mathrm{~km}<r<12 \mathrm{~km})$.

The derived equations can be applied to the evaluation of 
the maximum inter-story drift of any structure for any desired confidence level, depending on the importance of the structure. However, use of the statistical data obtained in this study is limited to steel GMRF structures where members are optimally chosen (using software such as SAP2000), but not for other special structures, like strong-beam/weak-column systems, or systems with weak stories.

\section{FURTHER STUDY WORK}

(a) Similar study on 3-bay steel moment-resisting frames has been conducted by the authors. The results, which will be published in a separate paper, have shown that the medians $\hat{\alpha}_{\theta}$ and dispersions $\delta_{\theta}$ are, in general, slightly less than those obtained in this study. Therefore, using statistic values of $\hat{\alpha}_{\theta}$ and $\delta_{\theta}$, obtained in this study to estimate the maximum inter-story drifts of multi-bay frame structures may obtain conservative values.

(b) Usually, the structural members are rolled steel sections, the dispersion of member size is believed to be small, and therefore, as compared to the modification factors in this study, its effect on the maximum inter-story drift ratio is negligible. However, if structural members are not rolled steel sections, then the member size should be considered as an additional factor in this rapid estimation method.

\section{ACKNOWLEDGMENTS}

This research investigation is funded by the National Science Council of Taiwan, R.O.C., under grant number NSC93-2211-E-035-015. This financial support is gratefully acknowledged. The reviewers' opinions and suggestions are also appreciated.

\section{APPENDIX A.: Derivation of Eqs. (4) and (5)}

Rewrite (1) as

$$
\alpha_{\theta}=\alpha_{u} \cdot \alpha_{M D O F} \cdot \alpha_{I N E L} \cdot \alpha_{P \Delta} \cdot \alpha_{S T}
$$

Since $\alpha_{u}, \alpha_{M D O F}, \alpha_{I N E L}, \alpha_{P \triangle}$ and $\alpha_{S T}$ are assumed lognormal in this study, their natural logs are jointly normal. For simplicity, let $\ln \alpha_{\theta}=\alpha_{0}, \ln \alpha_{u}=\alpha_{1}, \ln \alpha_{M D O F}=\alpha_{2}, \ln \alpha_{I N E L}=$ $\alpha_{3}, \ln \alpha_{P \Delta}=\alpha_{4}$ and $\ln \alpha_{S T}=\alpha_{5}$. Denote the means of the natural logs by $\mu_{0}, \mu_{1}, \mu_{2}, \mu_{3}, \mu_{4}$ and $\mu_{5}$, respectively. Taking the natural $\log$ on both sides of (A1), we obtain

$$
\alpha_{0}=\sum_{k=1}^{5} \alpha_{k}
$$

rewrite (A2) as

$$
\alpha_{0}=\sum_{k=1}^{5} \mu_{k}+\sum_{k=1}^{5}\left(\alpha_{k}-\mu_{k}\right)
$$

Taking the expectation on both sides of (A3) the mean and variance of $\alpha_{0}$ are obtained as follows:

$$
\begin{gathered}
\mu_{0}=\mu_{1}+\mu_{2}+\mu_{3}+\mu_{4}+\mu_{5} \\
\sigma_{\alpha_{0}}^{2}=\sum_{k=1}^{5} \sum_{l=1}^{5} E\left(\alpha_{k}-\mu_{k}\right)\left(\alpha_{l}-\mu_{l}\right)
\end{gathered}
$$

The exponential value of (A4) can be written as:

$$
e^{\mu_{0}}=e^{\mu_{1}} \cdot e^{\mu_{2}} \cdot e^{\mu_{3}} \cdot e^{\mu_{4}} \cdot e^{\mu_{5}}
$$

Equation (A6) can also be expressed by (A7):

$$
\hat{\alpha}_{\theta}=\hat{\alpha}_{u} \cdot \hat{\alpha}_{M D O F} \cdot \hat{\alpha}_{I N E L} \cdot \hat{\alpha}_{P \Delta} \cdot \hat{\alpha}_{S T}
$$

where the modification factors with hats denote medians. In (A5) the expectation term can be calculated numerically, i.e.:

$$
E\left[\left(\alpha_{k}-\mu_{k}\right)\left(\alpha_{l}-\mu_{l}\right)\right]=\frac{1}{n-1} \sum_{i=1}^{n}\left(\alpha_{k}-\mu_{k}\right)_{i}\left(\alpha_{l}-\mu_{l}\right)_{i}
$$

where $\mathrm{n}$ is the number of earthquakes considered for a structure. For example, for $\mathrm{k}=2$ and $1=3$, Eq. (A8) can be written as:

$$
\delta_{M D O F \cdot I N E L}=\frac{1}{n-1} \sum_{i=1}^{n}\left(\ln \alpha_{M D O F}-\ln \hat{\alpha}_{M D O F}\right)_{i} \cdot\left(\ln \alpha_{I N E L}-\ln \hat{\alpha}_{I N E L}\right)_{i}
$$

where $\delta_{\text {MDOF } \text { INEL }}$ is the covariance of the natural logs of the modification factors $\alpha_{M D O F}$ and $\alpha_{I N E L}$. Expanding (A5), we arrive at (5) of analysis procedure (i).

\section{APPENDIX B.: Member details and geometry for GMRF structure}

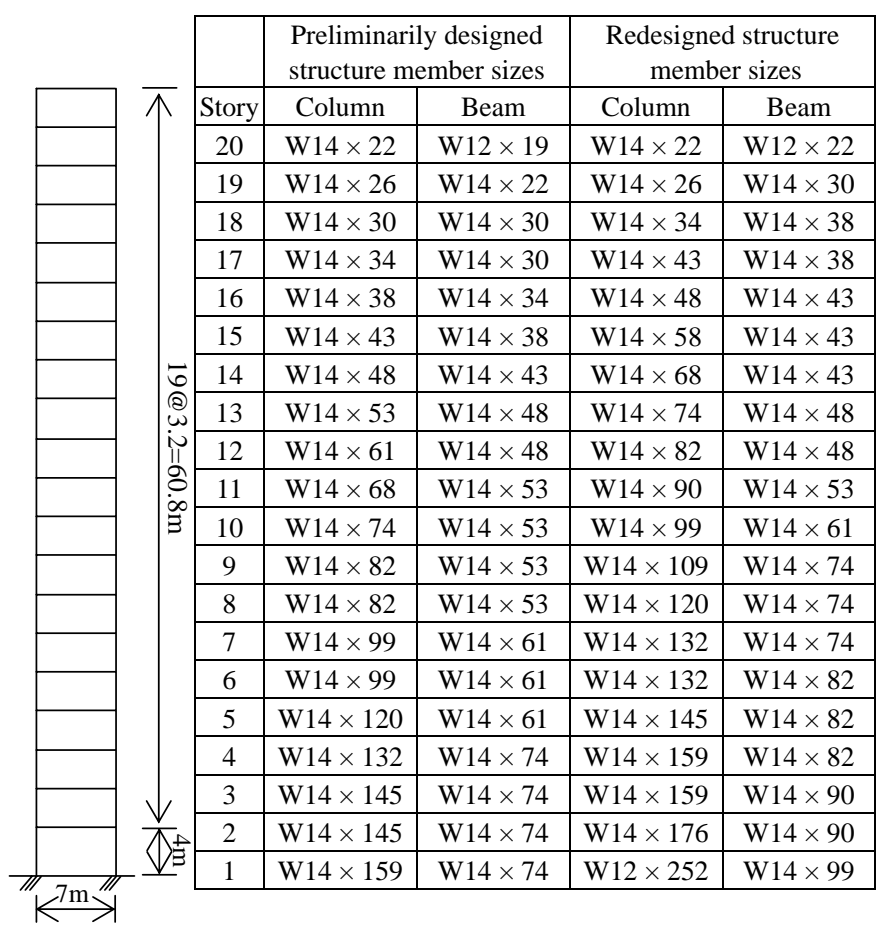




\section{REFERENCES}

1. Albanesi, T., Nuti, C., and Vanzi, I., "A simplified procedure to assess the seismic response of non-linear structures," Earthquake Spectra, Vol. 16, No. 4, pp. 715-734 (2000).

2. Balendra, T. and Huang, X., "Overstrength and ductility factors for steel frames designed according to BS 5950," Journal of Structural Engineering, Vol. 129, No. 8, pp. 1019-1035 (2003).

3. Benjamin, J. R. and Cornell, C. A., "Probability statistics and decision for civil engineers," McGraw-Hill Book Company (1970).

4. Bracci, J. B., Kunnath, S. K., and Rrinhorn, A. M., "Seismic performance and retrofit evaluation of reinforced concrete structures," Journal of Structural Engineering, Vol. 123, No. 1, pp. 3-10 (1997).

5. Chi, W. C., Dreger, D., and Kaverina, A., "Finite-source modeling of the 1999 Taiwan (Chi-Chi) earthquake derived from a dense strong-motion network," Bulletin of the Seismological Society of America, Vol. 91, pp. 1144- 1157 (2001).

6. Dalguer, L. A., Irikura, K., Riera, J. D., and Chiu, H. C., "The importance of the dynamic source effects on strong ground motion during the 1999 Chi-Chi, Taiwan, earthquake: Brief interpretation of damage distribution on buildings," Bulletin of the Seismological Society of America, Vol. 91, pp. 1112-1127 (2001).

7. Gupta, A. and Krawinkler, H., "Estimation of seismic drift demands for frame structures," Earthquake Engineering and Structural Dynamics, Vol. 29, No. 9, pp. 1287-1305 (2000).

8. Gupta, A. and Krawinkler, H., "Dynamic P-delta effects for flexible inelastic steel structures," Journal of Structural Engineering, Vol. 126, No. 1 pp. 145-154 (2000).

9. Gupta, A. and Krawinkler, H., "Relating the seismic drift demands of SMRFs to element deformation demands," Engineering Journal, second quarter, pp. 100-108 (2002).

10. Han, S. W. and Wen, Y. K., "Method of reliability-based seismic design. I: Equivalent non-linear system," Journal of Structural Engineering, Vol. 123, No. 3, pp. 256-265 (1997)

11. Jan, T. S., Liu, M. W., and Kao, Y. C., "An upper-bound pushover analysis procedure for estimating the seismic demands of hight-rise buildings,"
Journal of Engineering Structures, Vol. 26, No. 1, pp. 117-128 (2004).

12. Lin, C. Y., Chen, W. Z., and Jan, T. S., "On a process of rapid estimation of seismic demands for generic steel frame structures," Seismic Engineering, ASME, Vol. 8, pp. 135-147 (2005).

13. Ma, K. F., Mori, J., Lee, S. J., and Yu, S. B., "Spatial and temporal distribution of slip for the 1999 Chi-Chi, Taiwan, earthquake," Bulletin of the Seismological Society of America, Vol. 91, pp. 1069-1087 (2001).

14. Ministry of Domestic Affairs, Taiwan, "Steel design technical codes for steel buildings (2)—regulation and its explanation for steel limit design," (2001).

15. Ministry of Domestic Affairs, Taiwan, "Steel design technical codes for steel buildings (2)—regulation and its explanation for steel limit design," (2006).

16. Nassar, A. A. and Krawinkler, H., "Seismic demands for SDOF and MDOF systems," Report No. 95, John A. Blume Earthquake Engineering Research Certer, Department of Civil Engineering, Stanford University, (1991).

17. Rakesh, K. Goel. and Anil, K. Chopra, "Role of higher- "mode" pushover analyses in seismic analysis of buildings," Earthquake Spectra, Vol. 21, No. 4, pp. 1027-1041 (2005).

18. Tsai, K. C. and Li, J. W., "DRAIN 2D+, a general purpose computer program for static and dynamic analyses of inelastic 2D structures supplemented with a graphic processor VIEW2D," Report No. CEER/ R83-03, Center for Earthquake Engineering Research, National Taiwan University (1994).

19. Wilson, E. L. and Habibullah, A., "SAP-2000 integrated finite element analysis and design of structures," Computers and Structures, Inc. (1998).

20. Wu, C., Takeo, M., and Ide, S., "Source process of the Chi-Chi earthquake: A joint inversion of strong motion data and global positioning system data with multifault model," Bulletin of the Seismological Society of America, Vol. 91, pp. 1128-1143 (2001).

21. Zeng, Y. and Chen, C. H., "Fault rupture process of the 20 September 1999 Chi-Chi, Taiwan, earthquake," Bulletin of the Seismological Society of America, Vol. 91, pp. 1088-1098 (2001). 